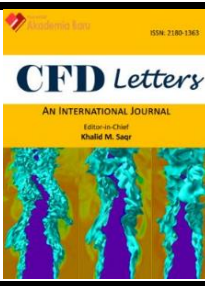

\title{
A CFD Simulation on the Performance of Slotted Propeller Design for Various Airfoil Configurations
}

\author{
Wan Mazlina Wan Mohamed ${ }^{1}$, Nirresh Prabu Ravindran², Parvathy Rajendran ${ }^{2,3^{*}}$ \\ Malaysia Institute of Transport (MITRANS), Universiti Teknologi MARA (UiTM), Shah Alam, Selangor, Malaysia \\ School of Aerospace Engineering, Universiti Sains Malaysia, Nibong Tebal, Pulau Pinang, Malaysia \\ Faculty of Engineering \& Computing, First City University College, Bandar Utama, 47800 Petaling Jaya, Selangor, Malaysia
}

ARTICLE INFO

\section{Article history:}

Received 19 January 2021

Received in revised form 11 February 2021

Accepted 12 February 2021

Available online 20 March 2021

\section{ABSTRACT}

The usage of slots has gained renewed interest in aerospace, particularly on propeller design. Most of the works have focused on improving the aerodynamic performance and efficiency. Modern research on propeller design aims to design propellers with high thrust performance under low torque conditions without any weight penalty. Although research on slotted design has been done before, none has been done to understand its impact on different airfoils on the propeller blade. Thus, this study aims to provide extensive research on slotted propeller design with various airfoil of different properties such as high Reynolds number, low Reynolds number, symmetrical, asymmetrical high lift, and low drag. This work has been investigated using computational fluid dynamics method to predict propeller performance for a small-scale propeller. The slotted blade designs' performance is presented in terms of thrust coefficient, power coefficient, efficiency, and thrust to power ratio. Here, the slotted APC Slow Flyer propeller blade's performance has been investigated for diverse types of airfoils with the shape and position of the slot is fixed which is a square-shaped at $62.5 \%$ of the chord length. The flow simulations are performed through threedimensional computational fluid dynamic software (ANSYS Fluent) to determine the thrust coefficient, power coefficient, efficiency, and thrust to power ratio measured in advancing flow conditions. Findings show that the slotted propeller design composed of symmetrical, high Reynolds number, high lift airfoils can benefit the most with slots' implementation. These improvements were $19.49 \%, 69.13 \%, 53.57 \%$ and $111.06 \%$ in terms of thrust, power, efficiency and trust to power ratio respectively.

APC Slow Flyer; Slotted propeller; groove; CFD; blade

\section{Introduction}

Since aircraft propellers' usage was pioneered, propeller usage never diminished due to its main advantage of low fuel consumption at low Reynolds number flight. Propeller manufacturers are continuously coming up with new innovative ways to keep the aerospace market propellers despite aerospace technology's evolving advancement. The propeller's characteristics, such as the diameter, the pitch, number of blades, shape of a blade, and airfoil selection used have been altered in a quest to produce a highly efficient propeller.

\footnotetext{
* Corresponding author.

E-mail address: aeparvathy@usm.my (Parvathy Rajendran)
} 
The study of slots' implementation in airfoils has been intended to alter the airfoil flow for better aerodynamic performance. The slotted propeller design concept works on a principle where the groove created along the propeller blade's length will slow down the airflow above the airfoil by creating a flow separation. The reduced velocity above the airfoil will cause the higher air pressure below of airfoil to create an upward force-producing lift, creating more thrust at lower torque [1].

Previous patented research mainly focuses on slot characteristics $[2,3]$ and how changes in terms of shape, size, number, and position of the slots on the airfoil will affect the blade's performance [4]. Reducing fuel consumption has become a driving factor for researching propeller design improvement with high thrust at low torque. Instead of focusing on the slot characteristics, this study solely focuses on a slotted design of the blade using different airfoils that vary with aerodynamic and physical properties such as symmetrical, asymmetrical, low Reynolds number, high Reynolds number, high lift, and low lift. This study will elucidate the effects and feasibility of a slot design application for various propeller types.

\section{Literature Review}

The propeller's design can alter any existing feature that the propeller's performance or adding a new feature on the propeller to improve its performance. For instance, increasing the number of blades positively impacts the blade's performance since the distribution of thrust and power is even in the propeller's wake. Therefore, the efficiency is slightly improved but not very significant. However, increasing the number of blades will demand more power from the engine to produce thrust. For a given power and thrust, the propeller blades will be narrow as the number of blades increase.

Having a large diameter propeller can significantly influence the performance, especially the propeller's efficiency. This is due to the ability to produce/initiate a greater fluid volume and better distribution of thrust and power compared to smaller diameter propeller. However, more power will be needed to rotate the propeller, can cause high fuel consumption and if it is an electric aircraft, the motor will potentially burn out.

Furthermore, having the right distribution of lift and drag coefficient along the propeller blade often points out airfoils' composition in the blade. When the blade rotates, the propeller blade tip rotates faster than the blade section closer to the hub. Hence, the selection of airfoil along the blade is crucial due to this very reason. Thus, it is crucial to understand the slotted design propellers' effect on various airfoil to appreciate its performance. Table 1 summarises the affected and performances of various parameters and factors in numerical propeller work.

The Reynolds number determines the pattern of fluid flow in different situations. Bartl and Sagmo et al., [5] investigated both numerically and experimentally the wing section's performance affected by the eight Reynolds number. The study showed that the lift and drag of the wing section are being influenced by Reynolds number lower than $0.7 \times 10^{5}$. McTavish and Feszty et al., [6] have conducted a similar study but on wind turbine rotor. The results showed that the wake expansion increases for the three-bladed propeller while the wake expansion is $30 \%$ to $50 \%$ narrower for the two-bladed rotor. The thrust coefficient is reduced for any geometrically scaled propeller when the Reynolds number reduced. 


\section{Table 1}

A summary of numerous factors that affect numerical propeller work

\begin{tabular}{lll}
\hline Factors & Study Name & Reynolds Number \\
\hline Reynolds & Bartl and Sagmo & 8 Reynolds number ranging from $0.5 \times$ \\
number & et al., [5] & $10^{5}$ to $6.0 \times 10^{5}$
\end{tabular}
Results

The $C_{L}$ increased at $R e=4.0 \times 10^{5}$

compared to at $\mathrm{Re}=0.7 \times 10^{5}$. The $C_{D}$ reduced at $\operatorname{Re}=2.0 \times 10^{5}$ compared to $\operatorname{Re}$ $=0.5 \times 10^{5}$

McTavish and Ranging from 3620 to 31400

Wake expansion for three blades Feszty et al., [6] propeller increases. Wake expansion reduced $30 \%$ to $50 \%$ for two-bladed propellers. Thrust coefficient reduces when the Reynolds number reduced.

Zanforlin and Ranging from $2.20 \times 10^{5}$ to $1.63 \times 10^{7}$ The L/D ratio increases within the $\mathrm{Re}$ range from $1.0 \times 10^{6}$ to $1.63 \times 10^{7}$.

Deluca [7]

Airfoil profile Panigrahi and

NACA 747A315, Eppler 420, Eppler

Best airfoil NACA 747A315 because it Mishra [8] 544, Eppler 855, FX74 CL5 140, NACA offers the highest $C_{L} / C_{D}$ 64(3)-418

Wang and Zhao NACA $8 \mathrm{H} 12$

Optimised NACA $8 \mathrm{H} 12$ had higher L/D and [9]

\begin{tabular}{lll}
\hline Blade profile & $\begin{array}{l}\text { Maizi and } \\
\text { Mohamed } \text { et al., } \\
{[10]}\end{array}$ & $\begin{array}{l}\text { Tip blade altered: Reference tip, Shark } \\
\text { tip, Original tip }\end{array}$ \\
Liu and Lin et al., & $\begin{array}{l}\text { Optimization of the Purdue model } \\
\text { blade }\end{array}$ \\
Cho and Lee [12] & $\begin{array}{l}\text { Untwisted and twisted blade } \\
\text { performance comparison }\end{array}$
\end{tabular}
higher Thrust than its original design.

Shark tip gave the best performance in terms of acoustics by Reducing sound by $7 \%$

Increase in blade efficiency

Twisted blade produced $1.9 \%$ higher power and $7.8 \%$ higher thrust than the untwisted blade

\begin{tabular}{|c|c|c|c|}
\hline \multirow[t]{3}{*}{ Slot shape } & $\begin{array}{l}\mathrm{Ni} \text { and Dhanak et } \\
\text { al., [13] }\end{array}$ & Shape constructed using two circles & Airfoil Lift and L/D ratio increases \\
\hline & $\begin{array}{l}\text { Belamadi and } \\
\text { Djemili et al., [14] }\end{array}$ & $\begin{array}{l}\text { Straight diagonal slot, creating a } \\
\text { passage between the upper and lower } \\
\text { surface of the airfoil }\end{array}$ & $\begin{array}{l}\text { Efficiency is inversely proportional to slot } \\
\text { size }\end{array}$ \\
\hline & $\begin{array}{l}\text { Rong and Cui et } \\
\text { al., [15] }\end{array}$ & Unique wave shape & $\begin{array}{l}\text { At a low flow rate, the vortex formation } \\
\text { reduced, and a uniform surface flow field } \\
\text { is formed. }\end{array}$ \\
\hline \multirow[t]{3}{*}{ Blade number } & $\begin{array}{l}\text { Asl and Monfared } \\
\text { et al., [16] }\end{array}$ & $\begin{array}{l}\text { No. of blades: } 2 \text { blades, 3blades } 4 \\
\text { blades }\end{array}$ & $\begin{array}{l}\text { The RPM of the rotor reduces } 10 \% \text { - } \\
12.5 \% \text { for adding each blade. }\end{array}$ \\
\hline & $\begin{array}{l}\text { Singh and } \\
\text { Nestmann [17] }\end{array}$ & No. of blades: 5 blades, six blades & $\begin{array}{l}\text { The flow guidance improved for an } \\
\text { increasing number of blades. However, } \\
\text { efficiency reduces when flow guidance } \\
\text { improves. }\end{array}$ \\
\hline & $\begin{array}{l}\text { Lieser and } \\
\text { Lohmann et al., } \\
{[18]}\end{array}$ & Two blades, four blades, six blades & $\begin{array}{l}\text { The six-bladed fans have the best acoustic } \\
\text { performance }\end{array}$ \\
\hline \multirow[t]{3}{*}{$\begin{array}{l}\text { Mesh } \\
\text { independency } \\
\text { study }\end{array}$} & $\begin{array}{l}\text { Almohammadi } \\
\text { and Ingham et al., } \\
\text { [19] }\end{array}$ & Seven different mesh resolutions & Higher mesh resolutions give fewer errors \\
\hline & $\begin{array}{l}\text { Wang and Li et al., } \\
{[20]}\end{array}$ & $\begin{array}{l}\text { Mesh resolution: } 5.5 \text { million, } 13.8 \\
\text { million, } 20.1 \text { million }\end{array}$ & $\begin{array}{l}\text { The error between computational and } \\
\text { experimental results reduced when mesh } \\
\text { resolution increase. }\end{array}$ \\
\hline & $\begin{array}{l}\text { Scuro and Angelo } \\
\text { et al., [21] }\end{array}$ & Up to 3.4 million cells & $\begin{array}{l}\text { Simulation results reached independence } \\
\text { after the mesh resolution of } 3.4 \text { million }\end{array}$ \\
\hline Mesh shape & $\begin{array}{l}\text { Li and Rong et al., } \\
{[22]}\end{array}$ & Hexahedral and tetrahedral & $\begin{array}{l}\text { Hexahedral gives better accuracy, and } \\
\text { Tetrahedral can be used for complex- } \\
\text { shaped domains }\end{array}$ \\
\hline
\end{tabular}


Biswas and Strawn Hexahedral and tetrahedral [23]

\begin{tabular}{lll} 
& Bahramian [24] & Hexahedral and tetrahedral \\
\hline $\begin{array}{l}\text { Turbulence } \\
\text { model }\end{array}$ & $\begin{array}{l}\text { Ayadi and } \\
\text { Nasraoui et al., } \\
{[25]}\end{array}$ & $\begin{array}{l}\text { Standard k- } \varepsilon \text {, Transition-k-kl- } \omega \text {, RNG } \\
\text { k- } \varepsilon \text {, Realizable k- } \varepsilon \text {, Transition-SST } \\
\text { models }\end{array}$ \\
& $\begin{array}{l}\text { Rezaeiha and } \\
\text { Montazeri et al., }\end{array}$ & $\begin{array}{l}\text { Spallart-Allmaras (SA), RNG k- } \varepsilon \text {, } \\
\text { Realizable k- } \varepsilon, \text { SST k- } \omega, \text { SST k- } \omega \text { with } \\
\text { additional intermittency transition } \\
\text { model (SSTI), k-kl- } \omega \text {, Transition SST } \\
\end{array}$ \\
& $\begin{array}{l}\text { (TSST) k- } \omega \text { models } \\
\text { Ru and Uddin et } \\
\text { Realizable k- } \varepsilon, \text { AKN k- } \varepsilon, \text { SST k- } \omega\end{array}$
\end{tabular}

The tetrahedral mesh had higher elements compared to hexahedral, and Hexahedral gives better accuracy Hexahedral mesh results re more accurate compared to tetrahedral $\mathrm{k}-\varepsilon$ is the best turbulence model to its high accuracy results

SST variant turbulence models produce results nearly similar to the experimental results compared to other turbulence models.

Realizable k- $\varepsilon$ showed the worst accuracy, AKN k- $\varepsilon$ had the best accuracy

Studies were conducted to investigate the effects of Reynolds number and the tip losses on the optimal aspect ratio of straight-bladed Vertical Axis Wind Turbine [7]. The result shows that the Reynold number strongly affects smaller sized wind turbines. As the wind turbine size decreases, tip loss is somehow cut off by Reynolds number's effects, thus affecting the variation of power coefficient of power.

The blade is a part of the propeller that is responsible for generating thrust. This is due to the twist and the airfoil composition of the blade. Researches such as Asl and Monfared et al., [16], Singh and Nestmann [17], and Lieser and Lohmann et al., [18] have demonstrated that the number of blades has an impact on the performance of the propeller. Their findings show that as the number of blades increases, the rotational speed decreases, and as the propeller efficiency reduced, the number of blades increases. Also, the propeller with a higher number of the blade has better acoustic performance than fewer blades.

Some researchers test the effectiveness of airfoils used in propellers by interchanging different existing airfoils on fixed blade profiles and analyzing the propeller's performance [8]. Wang and Zhao [9] have instead altered and optimized to create a new airfoil shape with a higher lift to drag ratio and produced more thrust than the original design.

Maizi and Mohamed et al., [10] and Liu and Lin et al., [11] proved that the blade's changing profile had improved the horizontal wind turbine's performance. It was found that the twisted blade produces higher power and higher thrust than the untwisted blade. Similarly, the study done by Cho and Lee [12] had the same purpose but on a helicopter propeller, also concluded that the optimized propeller shape showed improvement in efficiency and aerodynamic performance.

$\mathrm{Ni}$ and Dhanak et al., [13] and Belamadi and Djemili et al., [14] have proved that slots on turbine rotors have significantly affected their performance. The results showed that the slotted rotor design had increased the lift coefficient and the lift to drag ratio of the blade. The lift coefficient is reduced when the slot is near the leading edge and increases close to the trailing edge. Moreover, the efficiency of the blade is inversely proportional to the size of the slot. Rong and Cui et al., [15] worked on slotted centrifugal fans which also showed the same results, has explained that the slot plays an essential role in manipulating the boundary layer.

The mesh independence study finds the right mesh resolution to get accurate results by reducing the simulation's errors. The accuracy of the result can be determined by comparing the results with existing experimental results as done by Almohammadi and Ingham et al., [19], Scuro and Angelo et al., [21], and Wang and Li et al., [20]. These researches have proven that having higher mesh resolution gives the best simulation results. 
Mesh can also be generated using two shapes tetrahedral and hexahedral. These shapes have advantages for different purposes based on the geometrical construction of the parts being simulated. In terms of accuracy, Li and Rong et al., [22], Biswas and Strawn [23], and Bahramian [24] demonstrated that the tetrahedral mesh had higher mesh elements compared to hexahedral mesh in the same condition. Both researchers also concluded that the hexahedral mesh contributed to improving the solution accuracy compared to tetrahedral mesh.

The turbulence model is an essential mathematical construction that needs $t$ to be selected to determine the turbulence in fluid flow simulation. Widely used turbulence models such as the variants of Standard k- $\varepsilon$, Transition-k-kl- $\omega$, RNG k- $\varepsilon$, Realizable k- $\varepsilon$, and Transition-SST models have been tested by Almohammadi and Ingham et al., [19], Ayadi and Nasraoui et al., [25], Rezaeiha and Montazeri et al., [26] and Fu and Uddin et al., [27].

\section{Methodology}

This section will first elucidate the propeller model investigated, followed by the computational simulation parameters, the set computational parameters, and the mesh independence study.

\subsection{Propeller Model}

The propeller model chosen for the basis of this simulation is the $10 \times 7$ inches 2 bladed APC Slowflyer illustrated in Figure 1. The APC Slowflyer is well made for speeds at low Reynolds number due to its blade's design composed of 2 airfoils (i.e. the Eppler E63 and Clark Y). The Eppler E63 airfoil will be replaced with seven different airfoils with different aerodynamic performance, as shown in Table 2. Figures 2 and 3 illustrate the lift coefficient and the lift over the drag coefficient for eight airfoils.

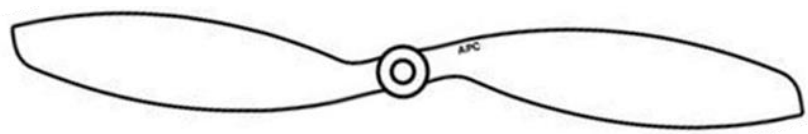

Fig. 1. Front view of APC Slowflyer propeller

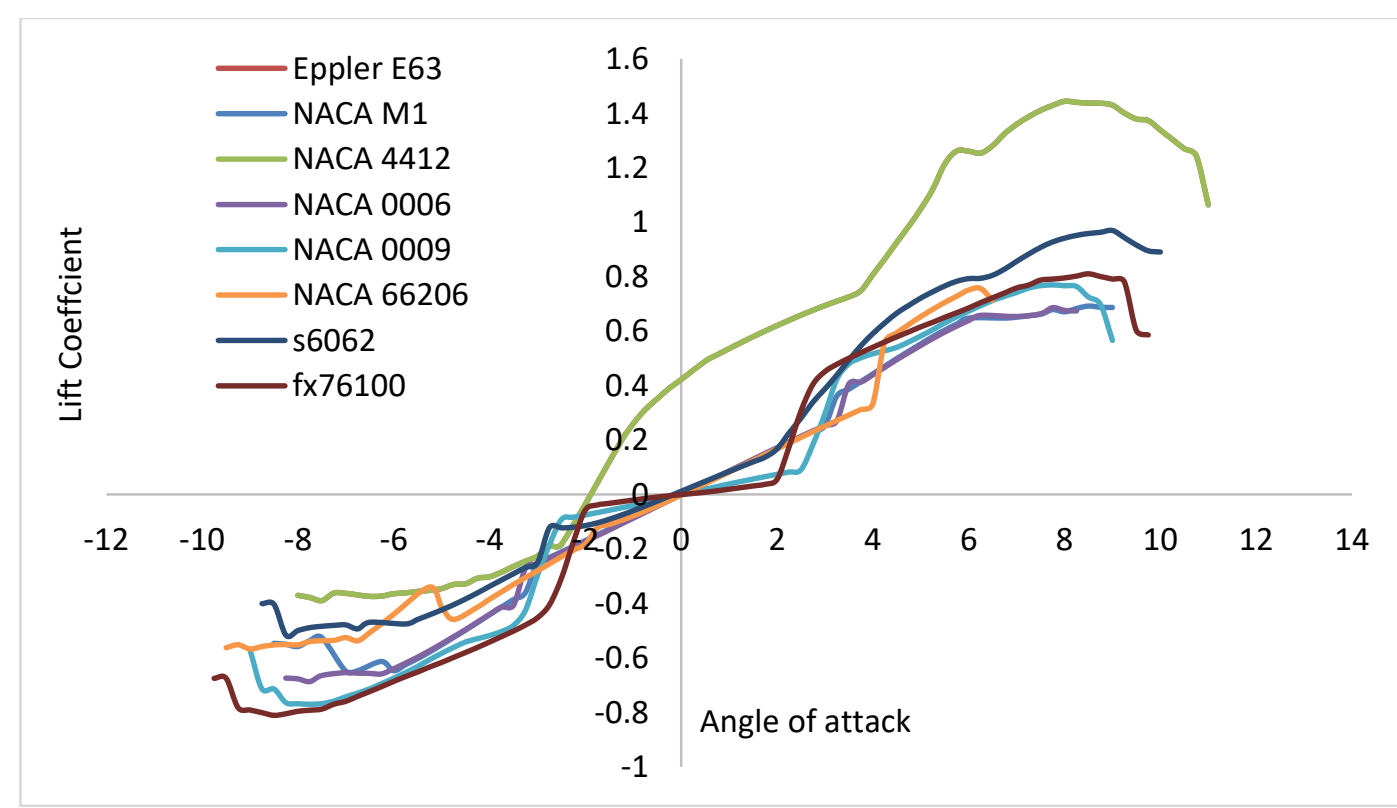

Fig. 2. The lift coefficient for eight selected airfoils 


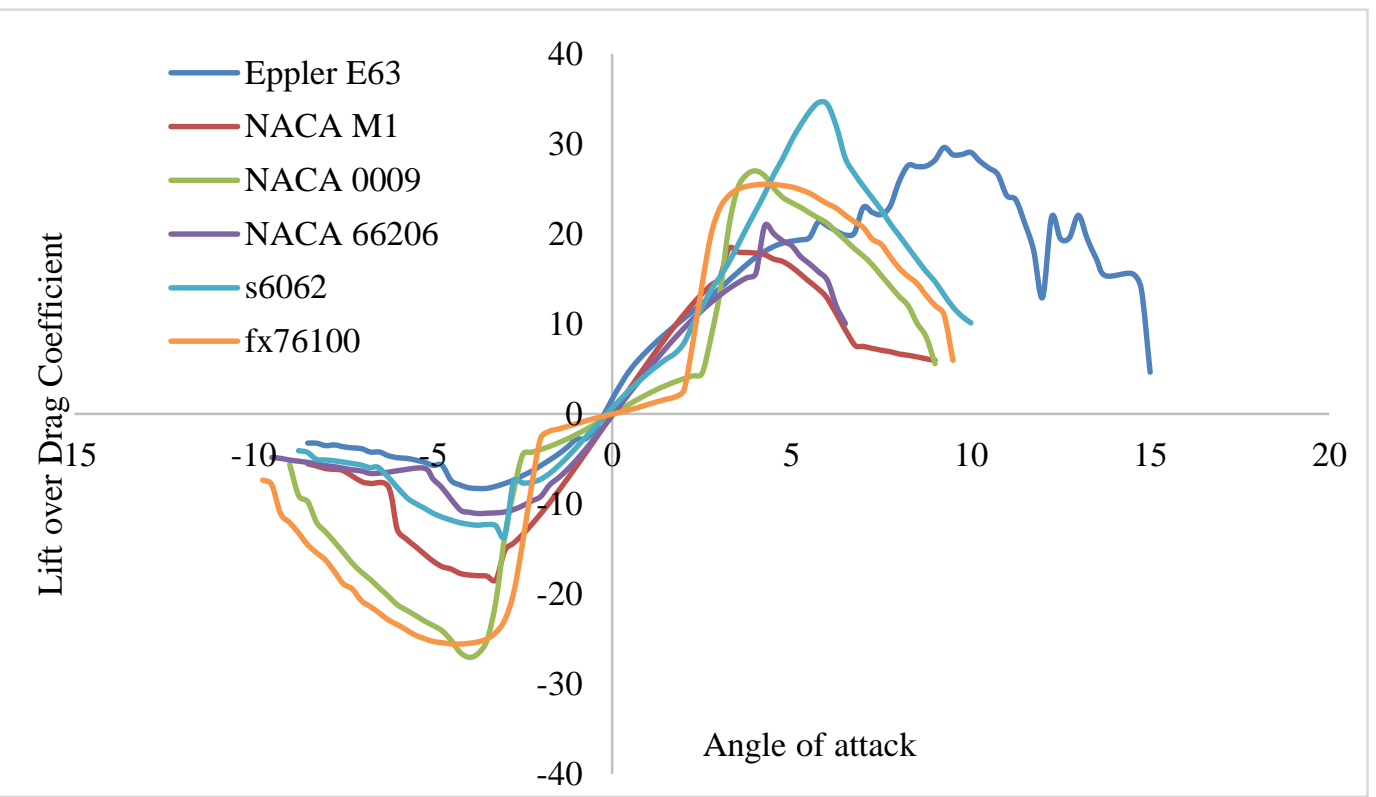

Fig. 3. The lift over drag coefficient for eight selected airfoils

Table 2

Category of the airfoil for baseline propeller

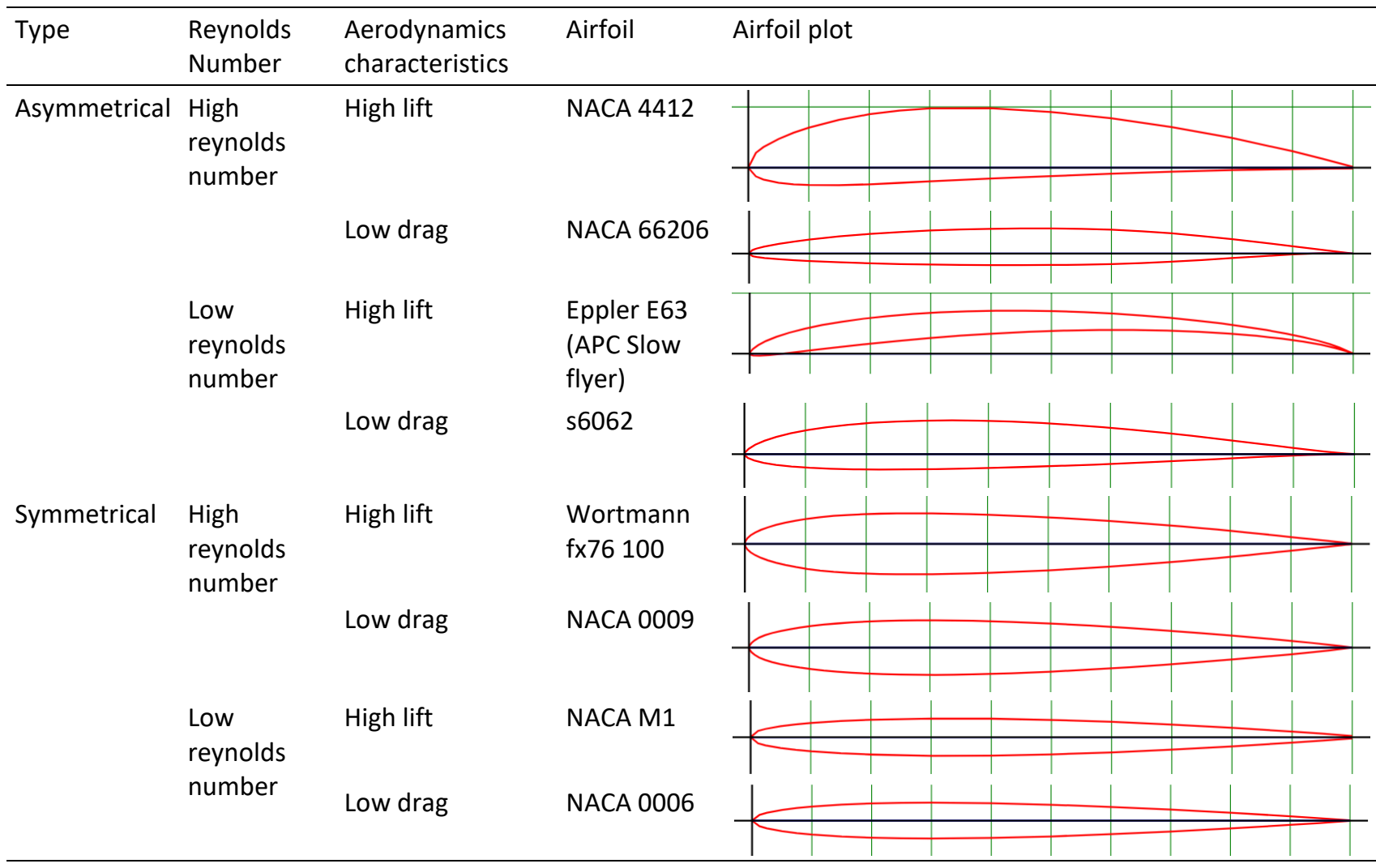

The eight different slotted propellers are designed using CATIA V5 with each propeller maintaining the APC Slowflyer's geometrical shape. There will be 16 propellers altogether designed; 8 baselines and 8 with square slotted at 62.5C, implementing the slotted airfoil design into each propeller. The dimension of the slot is $0.16 \mathrm{~mm} \times 0.836$ the same for all the propellers. Hence, the slot in the propeller will appear as a groove along the propeller blade. The chosen slot location of 
0.62.5C and its slot dimension significantly impact the performance compared to other locations and the baseline design, as shown on published preliminary work done earlier [28-30].

The slotted design has been implemented on the airfoil to create the flow separation, thus slowing down the airflow velocity. The reduction in airflow velocity over the propeller's airfoil will significantly affect the propeller's thrust, power, and efficiency. Later, the simulation's result on the slotted and baseline propeller design will be compared and discussed.

The thrust coefficient $\left(K_{T}\right)$, power coefficient $\left(K_{P}\right)$, torque coefficient $\left(K_{Q}\right)$, and the efficiency $(\eta)$ of the propeller are presented in Eq. (1-4) are four parameters that need to be analyzed to determine the slotted and the baseline propellers' performance. From the equations, $T(N)$ is Thrust, $P\left(N . \mathrm{ms}^{-1}\right.$ ) is power, $Q(\mathrm{~N} . \mathrm{m})$ is torque, $n(\mathrm{rps})$ is revolutions per second, $\mathrm{D}(\mathrm{m})$ is the propeller diameter, and $\rho\left(\mathrm{kgm}^{-3}\right)$ is the density of the fluid, and $\mathrm{J}$ is the advance coefficient.

$$
\begin{aligned}
& K_{T}=\frac{T}{\rho n^{2} D^{4}} \\
& K_{P}=\frac{P}{\rho n^{3} D^{5}} \\
& K_{Q}=\frac{Q}{\rho n^{2} D^{5}} \\
& \eta=J \frac{K_{T}}{K_{P}}
\end{aligned}
$$

\subsection{Computational Parameters}

The propeller's simulation is conducted and analyzed using Computational Fluid Dynamics software, ANSYS Fluent version 18.0. Computational parameters based on Table 3 need to be set for the simulation, similar to work published by Kutty and Rajendran et al., [30].

Table 3

Numerical computational parameters

\begin{tabular}{ll}
\hline Type & Pressure-based \\
\hline Inlet distance & $4 \mathrm{D}$ \\
Outlet distance & $4 \mathrm{D}$ \\
Enclosure & $0.4 \mathrm{D}$ \\
Diameter & $1.1 \mathrm{~d}$ \\
Turbulence model & Standard k- $\omega$ \\
Fluid & Air \\
Blade motion type & Mesh motion rotational \\
Relative specification & Absolute \\
Reference frame & Multiple reference frame \\
Inlet boundary type & Velocity inlet \\
Velocity inlet & Varies as per advanced ratio \\
Outlet boundary type & Outflow \\
Residual error & $1 x 10^{-5}$ \\
Pressure-velocity coupling & Simple scheme \\
Gradient & Least squares cell based \\
Interpolating scheme(momentum) & Second-order upwind \\
Interpolating scheme(turbulence kinetic energy) & First order upwind \\
Interpolating scheme(specific dissipation rate) & First order upwind \\
\hline
\end{tabular}


The simulation's flow domain is divided into 2, the rotating domain which enables the propeller to rotate and the stationary domain. The rotating domain is created in the Design-Modeler, embedded in ANSYS Fluent after the propeller's CAD file is transferred into ANSYS Fluent. The rotating domain is a cylinder with a diameter of 1.1D (1.1 $x$ diameter of the propeller) and a thickness of 0.4D ( $0.4 \times$ diameter of propeller) enclosing the propeller as shown in Figure 4.

The stationary domain is made of a cube with a height, width, and length of 8D ( $8 \times$ diameter of propeller) enclosing the rotating domain cylinder, as shown in Figure 5 . The stationary domain was design to imitate a wind tunnel test. The inlet and the outlet set on the stationary domain in Design Modeler are fixed adjacent to the XY plane since the propeller is rotating on the z-axis. The inlet's and the Outlet's distance from the propeller is set far enough to prevent the stationary region's circulation flow.

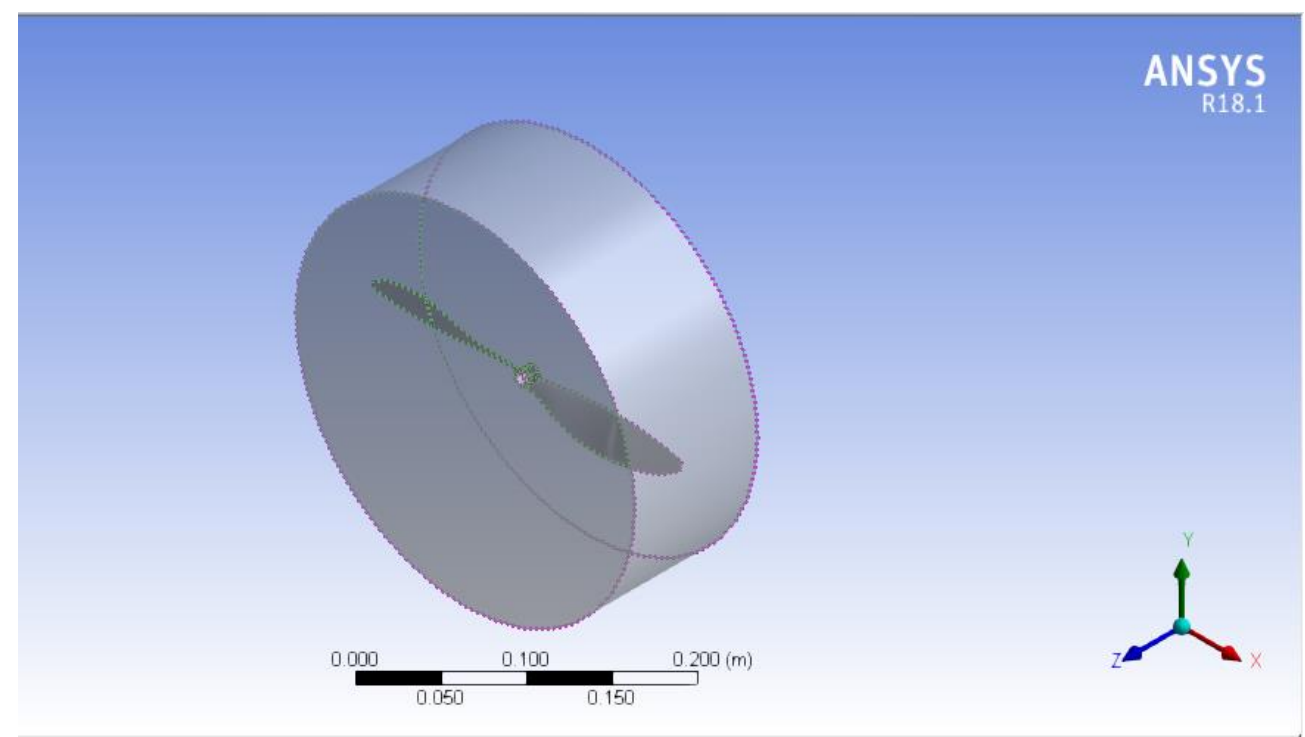

Fig. 4. Rotating domain of the fluid flow simulation

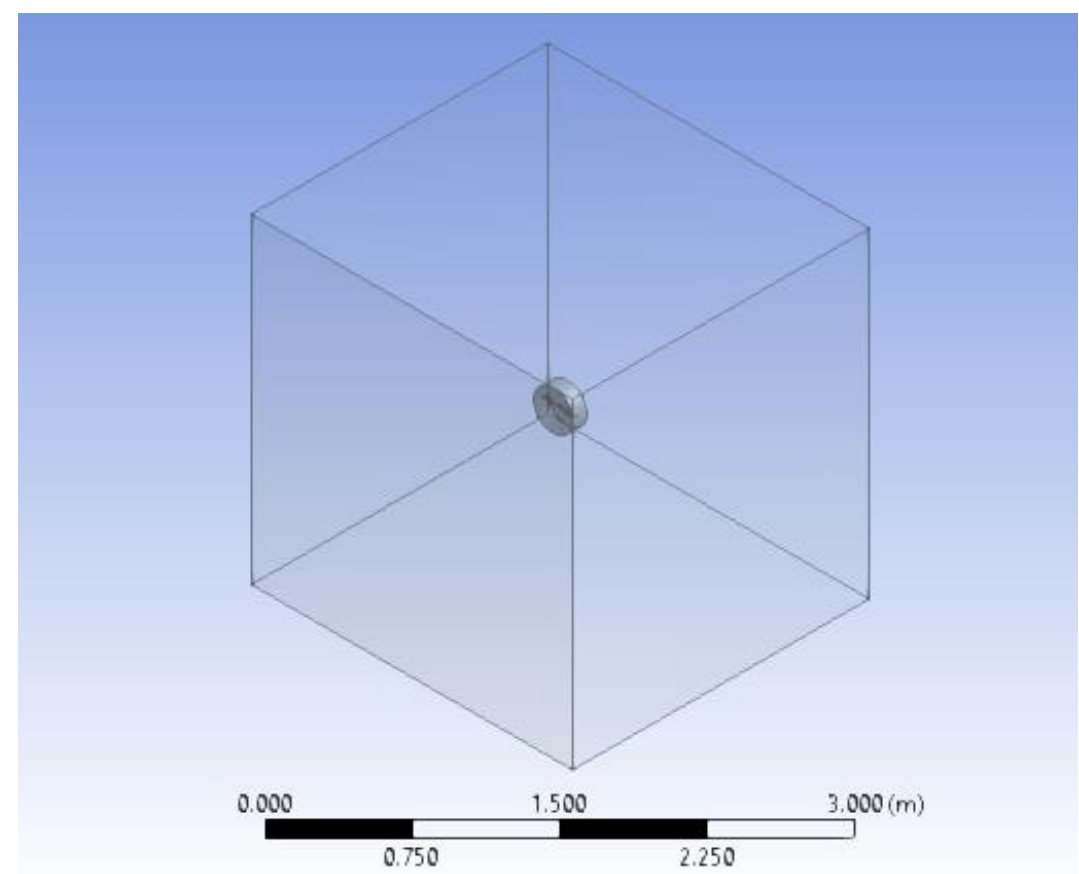

Fig. 5. The stationary domain of the fluid flow simulation 


\subsection{Boundary Condition}

The CFD simulation is done with a fixed free stream velocity of $6.6929 \mathrm{~ms}^{-1}$ with the advanced ratio given in Eq. (5). The chosen velocity is associated with the propeller's advance ratio of 0.527 rotating at 3008 revolutions per minute (rpm). Thus, the inlet velocity where the air travels are set at $6.6929 \mathrm{~ms}^{-1}$ while the outlet is set as the outflow. The chosen free stream velocity, advance ratio, and rpm were maintained based on previously published preliminary work, giving a computational model validation using an experimental model [29].

$J=\frac{V}{n D}$

A Multiple Reference Frame (MRF) technique is used to interact between the $3008 \mathrm{rpm}$ rotating domain and the stationary domain where the airspeed operates at $6.6929 \mathrm{~ms}^{-1}$ defined. A local frame transformation will be undergone in the interface between the rotating and stationary domains, allowing the fluid to travel from the inlet through the stationary domain to the rotating domain and finally flowing out. This allows the variable fluid flow from one cell zone to be used by the adjacent cell zone.

Since the simulation is running in a low Reynolds number, the $k-\omega$ turbulence model is chosen. The SIMPLE (Semi-Implicit Method for Pressure-Linked Equations) algorithm is used to achieve the pressure-velocity coupling. In the same section, the interpolating scheme for turbulence kinetic energy and specific dissipation rate is set as First Order Upwind and momentum the Second Order Upwind as per previous Kutty and Rajendran et al., [30] research work.

\subsection{Mesh Independency Study}

In this study, an unstructured tetrahedron mesh is used due to its ability to produce more cells or more nodes than any other mesh-type based on the same geometry [22]. Five different mesh types (Table 4) are analyzed with its settings as given in Table 5, from the standard mesh consisting of relatively the lowest number of cells to the fine mesh with the highest amount of cells.

Table 4

Five mesh grid type

\begin{tabular}{lll}
\hline Mesh & Elements & Nodes \\
\hline Standard & 403,278 & 79,783 \\
Coarse & $1,270,019$ & 198,791 \\
Mid & $2,110,938$ & 367,224 \\
Mid-Fine & $3,016,231$ & 568,312 \\
Fine & $4,223,072$ & 797,122 \\
\hline
\end{tabular}

Table 5

Mesh grid settings for midfine mesh [30]

\begin{tabular}{ll}
\hline Mesh size function & Curvature \\
\hline Relevance centre & Fine \\
Curvature normal angle & $40^{\circ}$ \\
Min size & $5 \times 10^{-5}$ \\
Max face size & $2.4718 \times 10^{-2}$ \\
Max tet size & 0.113440 \\
Growth Rate & 1.20 \\
Minimum Edge length & $2.5113 \times 10^{-3}$ \\
\hline
\end{tabular}


The best mesh was selected based on the percentage difference of result data between different values. Thus, the mid fine mesh grid has been selected for this analysis since 6 out of 8 propeller models investigated gave close to $10 \%$ deviation for both the $K_{T}$ and $K_{P}$, as bold in Table 6 . Out of the eight chosen propellers, only NACA 0009 and NACA 66206 did not have good agreement with the investigated parameters. Figure 6 shows a sample of the outcome of the mesh independency study for baseline and slotted propellers.

Table 6

Mesh independency study result comparison

\begin{tabular}{llll}
\hline Propellers & Mesh & $\Delta \% \mathrm{Kt}$ & $\Delta \% \mathrm{Kp}$ \\
\hline fx76100 & Standard to coarse & 15.230 & 82.316 \\
& Coarse to mid & 11.852 & 31.317 \\
& Mid to mid fine & 1.445 & 5.843 \\
& Mid fine to fine & 2.710 & 6.947 \\
NACA 4421 & Standard to coarse & 1.039 & 53.498 \\
& Coarse to mid & 12.449 & 15.845 \\
& Mid to mid fine & 10.899 & 7.477 \\
& Mid fine to fine & 1.043 & 51.553 \\
s6062 & Standard to coarse & 1.448 & 149.790 \\
& Coarse to mid & 8.089 & 40.837 \\
& Mid to mid fine & 9.646 & 21.505 \\
NACA M1 & Mid fine to fine & 5.446 & 8.486 \\
& Standard to coarse & 1.700 & 4.623 \\
& Coarse to mid & 11.238 & 49.781 \\
& Mid to mid fine & 5.685 & 7.460 \\
NACA 0006 & Mid fine to fine & 0.985 & 1.497 \\
& Standard to coarse & 0.163 & 49.784 \\
& Coarse to mid & 12.811 & 62.495 \\
& Mid to mid fine & 7.406 & 13.210 \\
& Mid fine to fine & 6.039 & 1.642 \\
NACA 0009 & Standard to coarse & 1.394 & 106.546 \\
& Coarse to mid & 12.961 & 258.819 \\
& Mid to mid fine & 11.779 & 13.575 \\
Slow flyer & Mid fine to fine & 5.151 & 59.048 \\
& Standard to coarse & 2.703 & 207.572 \\
& Coarse to mid & 12.627 & 14.066 \\
& Mid to mid fine & 12.279 & 11.405 \\
& Mid fine to fine & 8.698 & 3.945 \\
\hline & Mid to mid fine & 10.255 & 89.927 \\
& Mid fine to fine & 10.949 & 43.796 \\
& Standard to coarse & 1.355 & 25.909 \\
& & & \\
& &
\end{tabular}

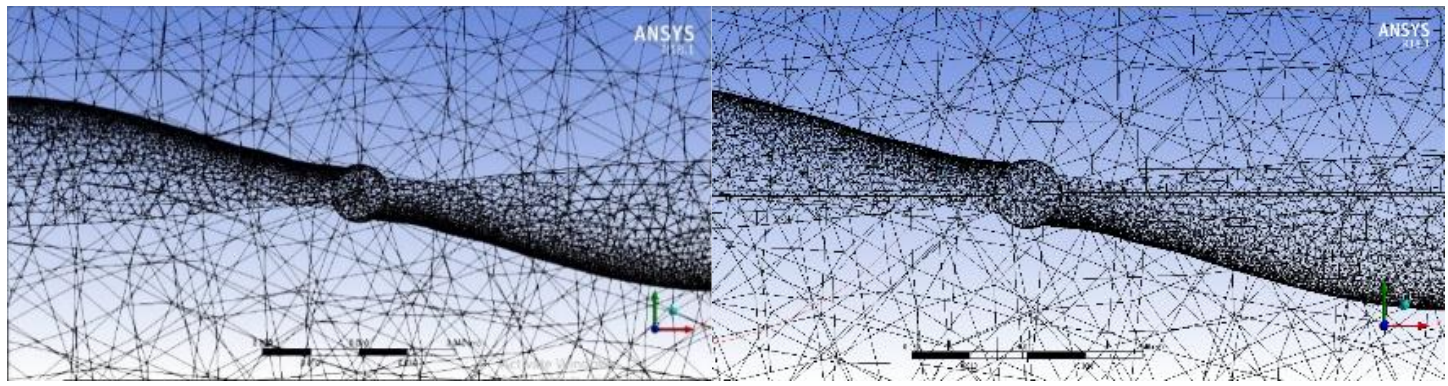

Fig. 6. Sample Mesh grid type for baseline (left) and slotted propeller (NACA4412) 


\section{Result and Discussion}

The three parameters analyzed to determine the aerodynamic performance of the baseline and slotted design propellers are the $\mathrm{K}_{T}, \mathrm{~K}_{\mathrm{P}}$, and $\eta$. Figure 7 presented a sample (i.e. NACA 66206) of the investigated propellers' velocity profile. The tip of the propeller experienced the highest velocity compared to the section near the hub. This is common in a rotating body where the further away an object or a part of a rotating object is away from the center of rotation, the faster it travels.

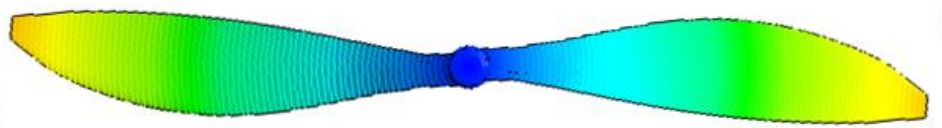

Fig. 7. Velocity and Pressure Profile of the baseline propeller

Figure 8 presents a baseline propeller's pressure profile modelled with the NACA 66206, where the front part of the blade experiences low-pressure airflow compared to the propeller's back. This pressure difference that produces the propeller thrust. Figure 9 shows the slotted propeller's pressure profile, and here it is noticeable that there is an increase in pressure around the slot in the front section of the propeller. Similar pressure profiles shown in Figures 8 and 9 have also modelled been for other investigated propellers. For these NACA 66206 propeller cases, the slot's presence on the propeller increases the pressure difference between the front and the back part of the propeller, thus increasing the thrust supported by the results shown in Table 7.

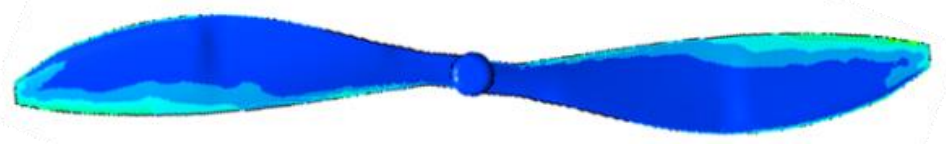

(a)

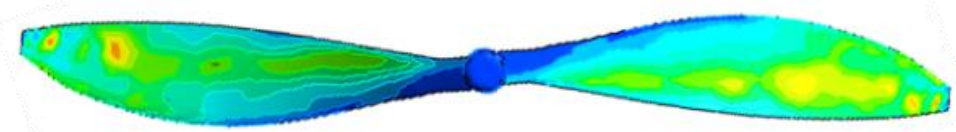

(b)

Fig. 8. (a) Front and (b) Back pressure profile of the baseline propeller

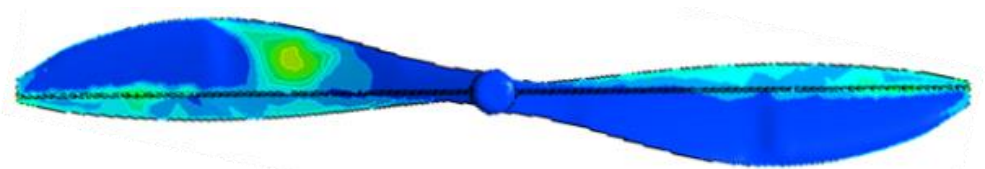

Fig. 9. Front pressure profile of the slotted propeller

Table 7

Differences in $\mathrm{K}_{\mathrm{T}}, \mathrm{K}_{\mathrm{P}}$, and $\eta$ between baseline and slotted propeller design

\begin{tabular}{lllll}
\hline Propeller Airfoil & $\Delta \mathrm{K}_{\mathrm{T}}(\%)$ & $\Delta \mathrm{K}_{\mathrm{P}}(\%)$ & $\Delta \eta(\%)$ & $\Delta \mathrm{K}_{\mathrm{T}} / \mathrm{K}_{\mathrm{P}}(\%)$ \\
\hline NACA 4412 & -4.11 & 30.17 & -5.21 & -26.33 \\
NACA 66206 & 3.21 & -13.82 & 19.76 & 53.57 \\
Eppler E63 (APC Slowflyer) & -4.30 & -41.96 & 6.84 & 16.85 \\
s6062 & -2.89 & -16.73 & 16.62 & 111.06 \\
fx76100 & 19.49 & -22.19 & 53.57 & 16.62 \\
NACA 0009 & -6.36 & -55.63 & 12.51 & -40.78 \\
NACA M1 & 0.17 & 69.13 & -37.13 & 64.90 \\
NACA 0006 & -7.67 & -20.99 & 16.85 & 19.76 \\
\hline
\end{tabular}


An improvement in the differences in $\mathrm{K}_{T}, \mathrm{~K}_{\mathrm{P}}, \eta$ and $\mathrm{K}_{\mathrm{T}} / \mathrm{K}_{\mathrm{P}}$ ratio between baseline and slotted propeller design are indicated with a positive value in Table 7 . Hence, the higher the percentage difference in Table 7 indicates an excellent slotted design. Figures 10, 11 and 12 illustrate the comparison of the thrust coefficient, power coefficient, and efficiency between the baseline and the slotted propeller design. Only three propellers show positive KT results due to the slot's implementation, and they are the propeller airfoil fx6100, NACA 66206, and NACA M1.

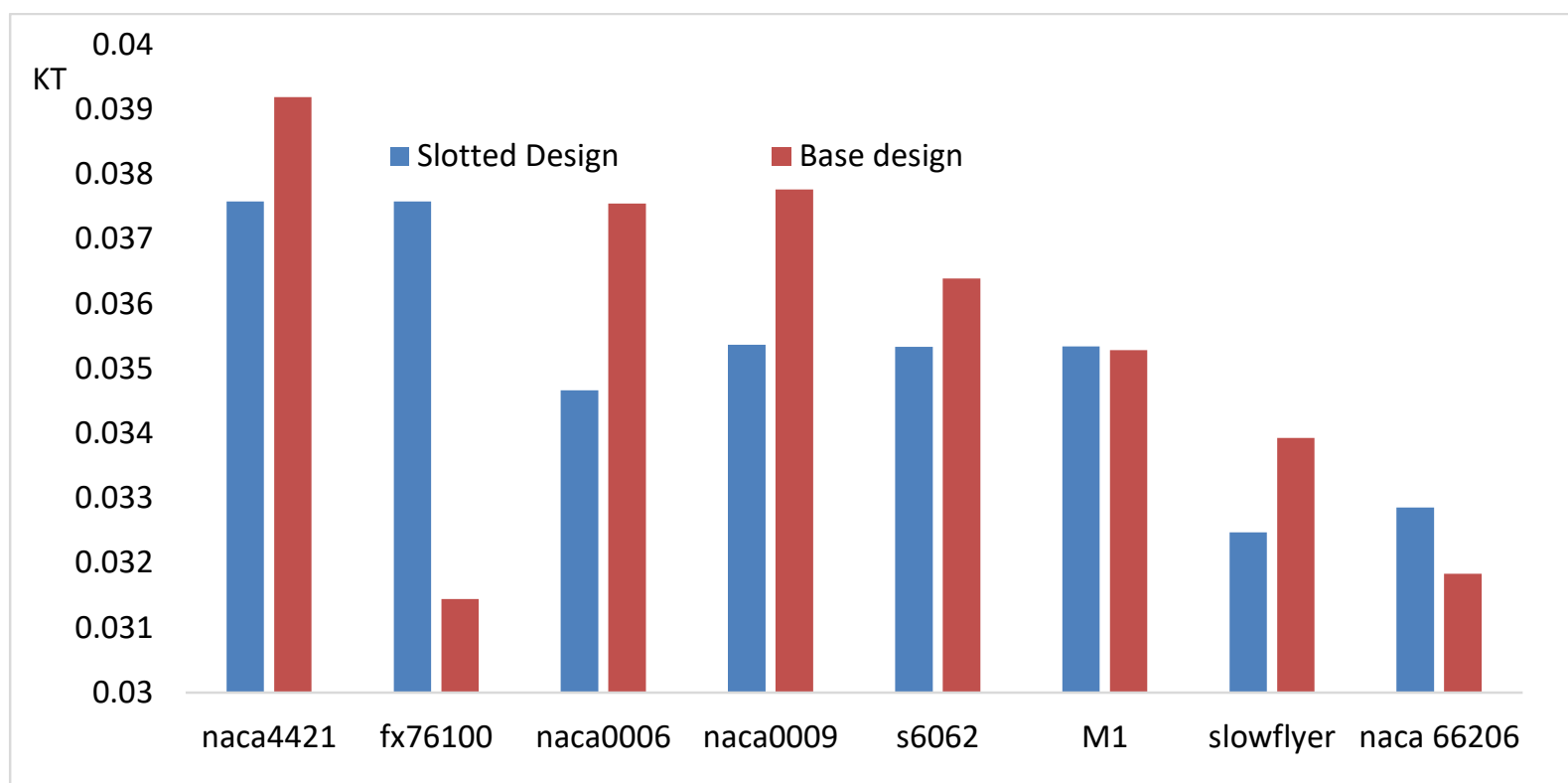

Fig. 10. Thrust coefficient of baseline and slotted design propellers

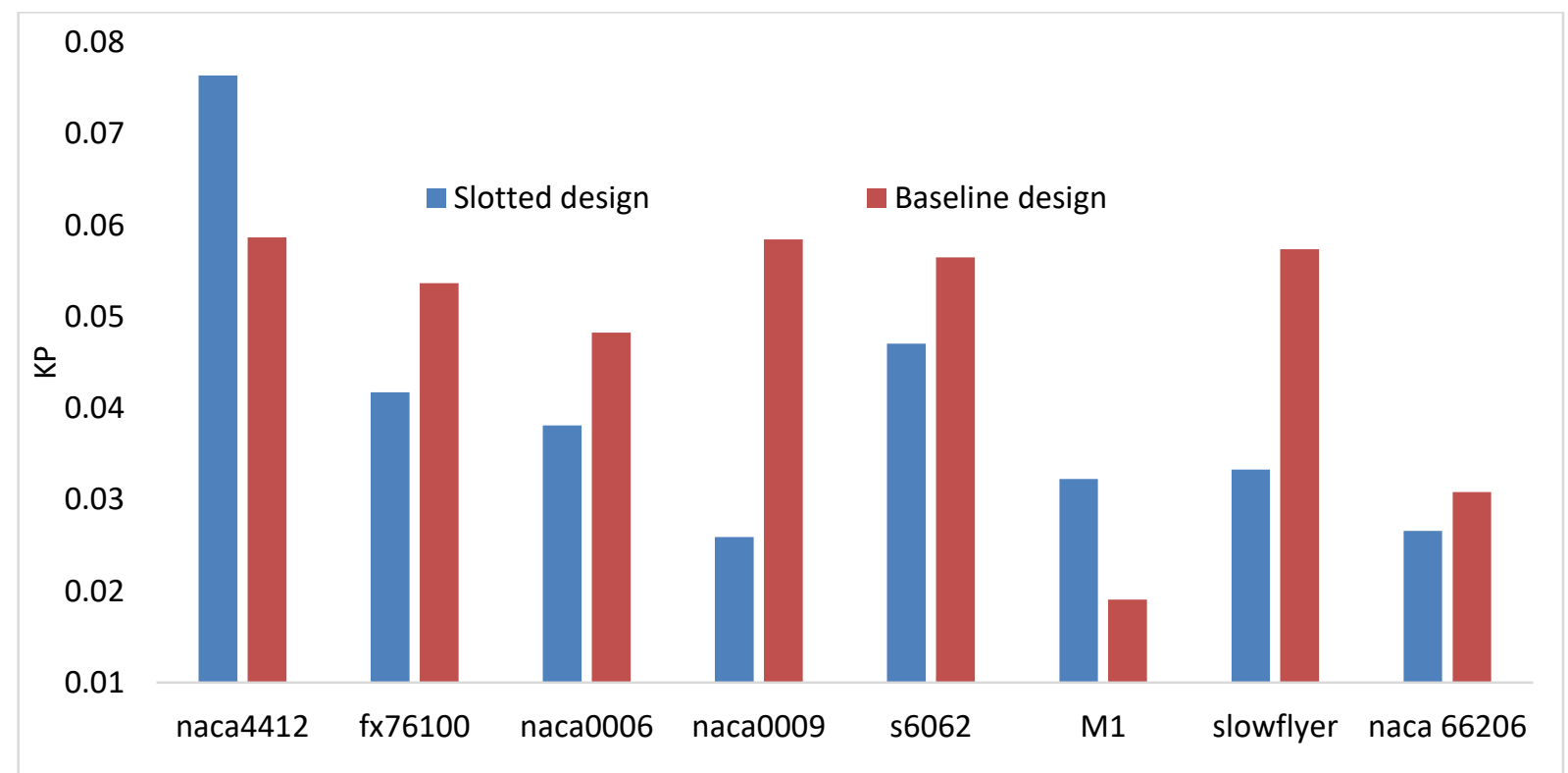

Fig. 11. Power coefficient of baseline and slotted design propellers 


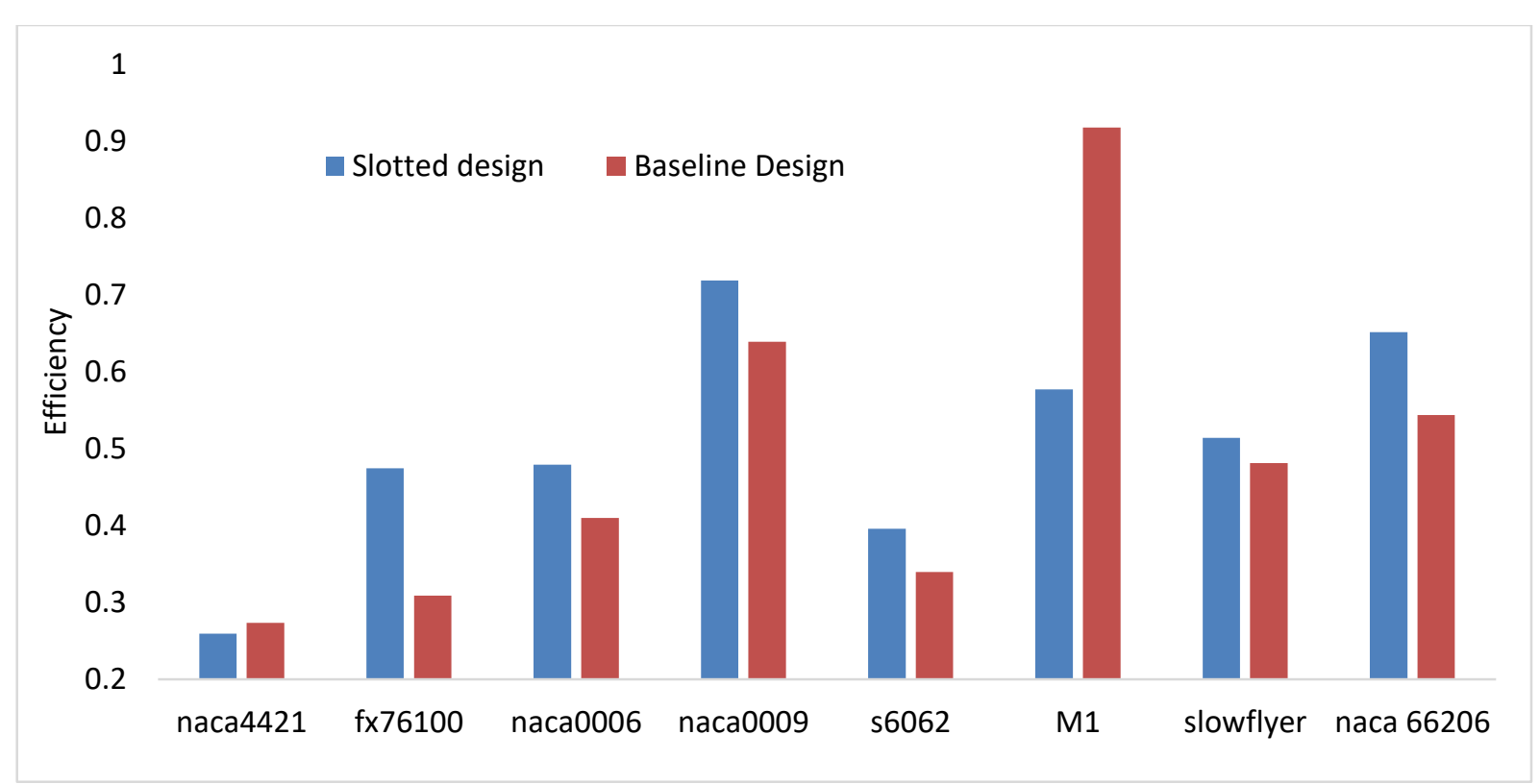

Fig. 12. The efficiency of baseline and slotted design propellers

The propeller with fx6100 airfoil, a symmetrical-high Reynolds number-high lift airfoil has produced the highest thrust which is $19.49 \%$ higher than its baseline design. Out of the three airfoils mentioned, the improved performance was followed by NACA 66206, an asymmetric-high Reynolds number-low drag airfoil which produced thrust 3.21\% from its baseline design. Finally, the NACA M1 which is a symmetrical-low Reynolds number-high lift airfoil which produces a thrust of only $0.19 \%$ more than its baseline design. Based on the results shown by these three airfoil propellers, it can be deduced that symmetric-high Reynolds-high lift propeller tends to produce higher thrust after the implementation of slots.

Based on the five underperforming airfoils, the slot's implementation on symmetrical-low drag airfoil, NACA 0009 and NACA 0006, and asymmetrical-low Reynold number airfoil, which is the Eppler E63 (APC Slowflyer) and s6062, harmed the thrust producing ability of the propeller. Only two out of 8 slotted propellers show positive results in power production than its baseline design counterparts. The NACA M1, a symmetrical-low Reynolds number-high lift airfoil produced the highest amount of power, increasing about $69.13 \%$ compared to its baseline design. This is followed by NACA 4412, an asymmetrical-high Reynolds number-high lift airfoil where the power increased by $30.17 \%$ after implementing the slot.

Six out of eight propellers have been shown a significant decrease in power production after implementing the slot. The highest disadvantage is NACA 0009, a symmetrical-low Reynolds numberlow drag airfoil where the power produced decreased significantly by $55.63 \%$ compared to its baseline design. It can be observed that out of the six underperforming airfoils, four of them are under the category of low drag airfoil (NACA 0009, NACA 0006, NACA 66206, and s6062). Thus, it can be elucidated that slotted design is not suitable for low drag airfoil in general.

Since efficiency is inversely proportional to the power coefficient, the two propellers with higher power coefficient, i.e. NACA M1 and NACA 4412 have lower efficiency. NACA M1 is a symmetricallow Reynolds number-high lift airfoil with a decrement of $37.13 \%$ efficiency, followed by the NACA 4412 an asymmetrical-high Reynolds number-high lift airfoil with decreased by $5.21 \%$ efficiency. The Wortmann fx76100, a symmetrical-high Reynolds number-high lift airfoil operates at the highest efficiency with an increment of $53.57 \%$ mainly due to the increment in thrust and decrement in power which justifies the airfoils significant efficiency increment. 
As for the $\mathrm{K}_{\mathrm{T}} / \mathrm{K}_{\mathrm{P}}$ ratio performance, all propellers have improved excerpt for NACA 4412 and NACA 0009. Overall, the best improvements of slotted design implementation were seen in NACA 66206, s6062 and NACA M1. Therefore, most of the propeller airfoils have benefited from the implementation of the slot. Implementing the slot on propeller airfoil has contributed significantly to most propellers compared to the thrust and power coefficient. Thus, implementing a slotted propeller design is an alternative method to increase the efficiency of a propeller.

\section{Conclusion}

This study has analysed the three parameters $K_{T}, K_{P}, \eta$, and $K_{T} / K_{P}$ ratio of sixteen different propellers that have been modelled; where eight of them are slotted propellers and the remaining eight are baseline propellers. These propellers have been modelled using different airfoils and have undergone simulation CFD simulation using ANSYS Fluent. Overall, the findings show that introducing a slot in a propeller does not always improve its performance. Only three out of eight propellers have been showing positive effects with a thrust, power, and efficiency increment of up to $19.49 \%, 69.13 \%$, and $53.57 \%$ respectively from the baseline propeller. NACA 66206, s6062 and NACA M1 have significant improvements in thrust to power ratio among the studied propeller variants. The propeller design composed with a symmetrical-high Reynolds number-high lift airfoils benefits the most in thrust and efficiency.

\section{Acknowledgement}

The authors acknowledge the support provided by Universiti Teknologi MARA (UiTM) and Malaysia Institute of Transport (MITRANS), UiTM 600-RMI/MITRANS_IRES 5/3(004/2017) and USM RU Grant Universiti Sains Malaysia 1001/PAERO/8014120 in carrying out this work.

\section{References}

[1] Seeni, Aravind, Parvathy Rajendran, and Hussin Mamat. "A CFD Mesh Independent Solution Technique for Low Reynolds Number Propeller." CFD Letters 11, no. 10 (2019): 15-30.

[2] Latif, Mohd Faruq Abdul, Muhammad Nur Othman, Qamar Fairuz Zahmani, Najiyah Safwa Khashi'ie, Beh Eik Zhen, Mohd Farid Ismail, and Ahmad Yusuf Ismail. "Optimization of Boundary Layer Separation Reduction Induced by The Addition of a Dimple Grid on Top of a Bluff Body." Journal of Advanced Research in Fluid Mechanics and Thermal Sciences 64, no. 2 (2019): 173-182.

[3] Merryisha, Samuel, and Parvathy Rajendran. "Experimental and CFD Analysis of Surface Modifiers on Aircraft Wing: A Review." CFD Letters 11, no. 10 (2019): 46-56.

[4] Seeni, A., P. Rajendran, and H. A. Kutty. "A Critical Review on Slotted Design for Propellers." In IOP Conference Series: Materials Science and Engineering, vol. 370, no. 1, p. 012023. IOP Publishing, 2018. https://doi.org/10.1088/1757-899x/370/1/012023

[5] Bartl, Jan, Kristian F. Sagmo, Tania Bracchi, and Lars Sætran. "Performance of the NREL S826 airfoil at low to moderate Reynolds numbers-A reference experiment for CFD models." European Journal of MechanicsB/Fluids 75 (2019): 180-192. https://doi.org/10.1016/i.euromechflu.2018.10.002

[6] McTavish, S., Daniel Feszty, and Fred Nitzsche. "Evaluating Reynolds number effects in small-scale wind turbine experiments." Journal of Wind Engineering and Industrial Aerodynamics 120 (2013): 81-90. https://doi.org/10.1016/i.jweia.2013.07.006

[7] Zanforlin, Stefania, and Stefano Deluca. "Effects of the Reynolds number and the tip losses on the optimal aspect ratio of straight-bladed Vertical Axis Wind Turbines." Energy 148 (2018): 179-195. https://doi.org/10.1016/i.energy.2018.01.132

[8] Panigrahi, Durga Charan, and Devi Prasad Mishra. "CFD simulations for the selection of an appropriate blade profile for improving energy efficiency in axial flow mine ventilation fans." Journal of Sustainable Mining 13, no. 1 (2014): 15-21. https://doi.org/10.7424/jsm140104

[9] Wang, Qing, and Qijun Zhao. "Rotor aerodynamic shape design for improving performance of an unmanned helicopter." Aerospace Science and Technology 87 (2019): 478-487. https://doi.org/10.1016/j.ast.2019.03.006 
[10] Maizi, M., M. H. Mohamed, R. Dizene, and M. C. Mihoubi. "Noise reduction of a horizontal wind turbine using different blade shapes." Renewable Energy 117 (2018): 242-256. https://doi.org/10.1016/j.renene.2017.10.058

[11] Liu, Jing, Htet Lin, Srinivasa Rao Purimitla, and Mohan Dass ET. "The effects of blade twist and nacelle shape on the performance of horizontal axis tidal current turbines." Applied Ocean Research 64 (2017): 58-69. https://doi.org/10.1016/i.apor.2017.02.003

[12] Cho, Jinsoo, and Seung-Chul Lee. "Propeller blade shape optimization for efficiency improvement." Computers \& fluids 27, no. 3 (1998): 407-419. https://doi.org/10.1016/s0045-7930(97)00035-2

[13] Ni, Zao, Manhar Dhanak, and Tsung-chow Su. "Improved performance of a slotted blade using a novel slot design." Journal of Wind Engineering and Industrial Aerodynamics 189 (2019): 34-44. https://doi.org/10.1016/i.jweia.2019.03.018

[14] Belamadi, Riyadh, Abdelouaheb Djemili, Adrian Ilinca, and Ramzi Mdouki. "Aerodynamic performance analysis of slotted airfoils for application to wind turbine blades." Journal of Wind Engineering and Industrial Aerodynamics 151 (2016): 79-99. https://doi.org/10.1016/i.jweia.2016.01.011

[15] Ni, Zao, Manhar Dhanak, and Tsung-chow Su. "Improved performance of a slotted blade using a novel slot design." Journal of Wind Engineering and Industrial Aerodynamics $189 \quad$ (2019): 34-44. https://doi.org/10.1016/j.proeng.2015.11.309

[16] Asl, Hamid Ahmadi, Reza Kamali Monfared, and Manouchehr Rad. "Experimental investigation of blade number and design effects for a ducted wind turbine." Renewable Energy 105 (2017): $334-343$. https://doi.org/10.1016/i.renene.2016.12.078

[17] Singh, Punit, and Franz Nestmann. "Experimental investigation of the influence of blade height and blade number on the performance of low head axial flow turbines." Renewable Energy 36, no. 1 (2011): $272-281$. https://doi.org/10.1016/i.renene.2010.06.033

[18] Lieser, J. A., D. Lohmann, and C-H. Rohardt. "Aeroacoustic design of a 6-bladed propeller." Aerospace science and technology 1, no. 6 (1997): 381-389. https://doi.org/10.1016/s1270-9638(97)90012-2

[19] Almohammadi, K. M., D. B. Ingham, L. Ma, and M. Pourkashan. "Computational fluid dynamics (CFD) mesh independency techniques for a straight blade vertical axis wind turbine." Energy 58 (2013): $483-493$. https://doi.org/10.1016/i.energy.2013.06.012

[20] Wang, C., X. Li, X. Chang, and W. P. Xiong. "Numerical simulation of propeller exciting force induced by millingshape ice." International Journal of Naval Architecture and Ocean Engineering 11, no. 1 (2019): $294-306$. https://doi.org/10.1016/j.ijnaoe.2018.06.004

[21] Scuro, N. L., Edvaldo Angelo, Gabriel Angelo, and D. A. Andrade. "A CFD analysis of the flow dynamics of a directlyoperated safety relief valve." Nuclear Engineering and Design 328 (2018): $321-332$. https://doi.org/10.1016/i.nucengdes.2018.01.024

[22] Li, Hao, Li Rong, and Guoqiang Zhang. "Reliability of turbulence models and mesh types for CFD simulations of a mechanically ventilated pig house containing animals." Biosystems Engineering 161 (2017): 37-52. https://doi.org/10.1016/i.biosystemseng.2017.06.012

[23] Biswas, Rupak, and Roger C. Strawn. "Tetrahedral and hexahedral mesh adaptation for CFD problems." Applied Numerical Mathematics 26, no. 1-2 (1998): 135-151. https://doi.org/10.1016/s0168-9274(97)00092-5

[24] Bahramian, Alireza. "Simultaneous effects of mesh refinement, grid configuration and wall boundary condition on prediction of pressure gradients and velocity profiles of microparticles in a conical fluidized bed." Particuology 43 (2019): 123-136. https://doi.org/10.1016/i.partic.2018.04.003

[25] Ayadi, Ahmed, Haithem Nasraoui, Abdallah Bouabidi, Zied Driss, Moubarak Bsisa, and Mohamed Salah Abid. "Effect of the turbulence model on the simulation of the air flow in a solar chimney." International Journal of Thermal Sciences 130 (2018): 423-434. https://doi.org/10.1016/j.ijthermalsci.2018.04.038

[26] Rezaeiha, Abdolrahim, Hamid Montazeri, and Bert Blocken. "On the accuracy of turbulence models for CFD simulations of vertical axis wind turbines." Energy $180 \quad$ (2019): 838-857. https://doi.org/10.1016/j.energy.2019.05.053

[27] Fu, Chen, Mesbah Uddin, and A. Clay Robinson. "Turbulence modeling effects on the CFD predictions of flow over a NASCAR Gen 6 racecar." Journal of Wind Engineering and Industrial Aerodynamics 176 (2018): 98-111. https://doi.org/10.1016/i.jweia.2018.03.016

[28] Seeni, Aravind. "Aerodynamic Performance Characterization of Slotted Propeller: Part B Effect of Angle." INCAS Bulletin 11, no. 4 (2019): 155-170. https://doi.org/10.13111/2066-8201.2019.11.4.14

[29] Kutty, Hairuniza Ahmed, Parvathy Rajendran, and Akshay Mule. "Performance analysis of small scale UAV propeller with slotted design." In 2017 2nd International Conference for Convergence in Technology (I2CT), pp. 695-700. IEEE, 2017. https://doi.org/10.1109/i2ct.2017.8226219

[30] Kutty, Hairuniza Ahmed, and Parvathy Rajendran. "3D CFD simulation and experimental validation of small APC slow flyer propeller blade." Aerospace 4, no. 1 (2017): 10. https://doi.org/10.3390/aerospace4010010 